\title{
Study on Utilization Pattern of Pulmonary Inhalers in Inpatient, Bhagwan Mahaveer Jain Hospital, Bangalore, India
}

\author{
Shivah Karamian *, Mahdieh Soleimani \\ Doctor of pharmacy, Department of pharmacy practice, Aditya Bangalore Institute of Pharmacy Education and \\ Research, Bangalore, India \\ Corresponding author: Shivah Karamian
}

\begin{abstract}
Objective: To study on utilization pattern of pulmonary inhalers in inpatient, Bhagwan Mahaveer Jain Hospital, Bangalore, India.

Methods: The proper inhalation technique was assed using the questionnaires there were 11 steps for MDI and 12 steps for MDI + spacer each correct technique carried a score of 1 and wrong technic carried 0.The adherence to the inhaler technique was assed using the formula correct dose/incorrect dose*100 and the reasons for non-adherence was also noted. The therapeutic inappropriateness of prescribed inhalers and antiasthmatic drugs is determined with standard guidelines. The cost involved in use of inhalers in therapeutic inappropriateness also considered.

Results: In our study population about 10.8\% asthmatics and $20 \%$ COPD patients were prescribed with budesonide MDI. About 10\% asthmatics and 9.1 COPD patients were prescribed with budesonide MDI+spacer. About $4.1 \%$ asthmatics and $2.5 \%$ coped patients were prescribed with salbutamol MDI. About $17 \%$ asthmatics and $10 \%$ copd patients were prescribed with mdi ipratropium and $8 \%$ asthmatics and $12.5 \%$ coped patients were prescribed with ipratropium MDI+spacer. When the knowledge regarding the usage of inhalers was assed using standard questionnaire which had 11 steps for MDI and 12 steps for MDI+spacer each questionnaire had scoring of 0 representing not performing the step, 1 representing following the step the scores were high after pharmacist intervention when compared to before pharmacist intervention

Conclusion: The present results highlight the need for pharmacist interventions aimed at improving adherence to inhalers in coped and asthmatic patients.
\end{abstract}

Keywords: inhaler usage, steps for inhaler usage, pulmonary inhalers

\section{INTRADACTION}

Inhaled therapy is the cornerstone in the management of asthma and chronic obstructive pulmonary disease (COPD). There are two main groups of inhaler devices: metered dose inhalers (MDI) and dry powder inhalers (DPI). Many devices have been developed and each has specificities on how to prepare the dose and deliver the drug to the airways. Although different devices have technological improvements to airway drug delivery, important limitations remain. 1 In fact, decades after the introduction of inhaler devices, their incorrect use remains an obstacle to achieve optimal disease outcomes. [7]

The correct use of inhaler devices is one of the most important aspects to be taken into account when evaluating individuals with asthma or COPD, and guidelines [4,5]emphasize the importance of assessing inhaler technique to improve the efficiency of drug delivery. Furthermore, it is recognized that inadequate use of inhaler devices is one of the most common reasons for failure to achieve asthma control. [4] A recent review reports a high percentage of inhaler technique errors, but with great variability among studies. [8]

Most patients with asthma or chronic obstructive pulmonary disease (COPD) require drug treatment with inhalation the major route of administration. The majority of asthma and COPD patients use their pressurised metered-dose inhaler (pMDI) incorrectly [2,6]. Major reasons for this are failure by patients to coordinate actuation with inhalation and failure to use a slow and deep inhalation $[1,2$, and 6]. Dry powder inhalers (DPIs) were developed with the intention of preventing errors in the co-ordination of actuation and inhalation. With a DPI, the act of inhalation de-aggregates ('breaks up') and releases the metered dose of drug, thereby removing the need for a patient to coordinate actuation with inhalation.

The incidence of asthma in New Zealand is one of the highest incidence rates in the world, affecting approximately $16 \%$ of adults in the population. The incidence is even greater for Maori $(22 \%)$ and Pacific people (20\%). 2 Hospitalisation rates for asthma have more than doubled in the last 30 years, with rates of 1 per 1000 
for those older than 15 years.4 Similarly the incidence of Chronic Obstructive Pulmonary Disease (COPD) is increasing in New Zealand, affecting approximately 200000 adults. [3]

In recent years, the prevalence of obstructive pulmonary diseases including asthma and chronic obstructive pulmonary disease (COPD) has shown a steady increase, with a corresponding increase in their social and economic impact. Bronchial asthma and COPD are two chronic obstructive airway diseases that exact an enormous toll on the patients, healthcare providers and the society. India has an estimated 15 to 20 million asthmatics. Rough estimates indicate a prevalence of between $10 \%$ and $15 \%$ in children in the age range of five to eleven years. The median prevalence rates of COPD were assessed as $5 \%$ for males and 2.7 $\%$ for female subjects of over 30 years of age. In India, COPD was accounted for $2.8 \%$ of the total deaths in 1990 and it was expected to rise to $6.5 \%$ deaths by 2020. Much of the morbidity from asthma is believed to be due to factors such as the denial of having a chronic condition, poor knowledge about the disease process and medication use, poor understanding about the use of inhalers and poor self-management. Patient decisions to follow the recommended treatment are likely to be influenced by their beliefs about medicines, as well as their beliefs about the illness that the medication is intended to treat or prevent. [9]

\section{MATERIALS AND METHODS}

Study design:

- Study conducted in inpatient department at a tertiary care hospital. Bhagwan Mahaveer Jain Hospital (BMJH)

\section{Source of data and Materials:}

- Inpatient case sheets

- Inpatient medication charts

- Nurse notes

- Physician notes

- Laboratory investigation charts

- Patients Interview

Inclusive Criteria:

- All inpatient which suffering from asthma and COPD.

\section{Exclusion Criteria:}

Pregnant women suffering from asthma and COPD

- Patients not receiving inhalers

Method of collection of data:

- The case charts from inpatient department receiving inhalers will be randomly selected on daily basis and will be reviewed for inhaler therapy.

\section{Methods:}

A hospital based prospective interventional study is conducted in the Pulmonology department of Bangalore Baptist hospital. Patients diagnosed with COPD/Asthma. The patient demographics and all medically relevant information is noted in a predefined data collection form.

A total of 180 inpatients were included in this study. Prescriptions and treatment chart of inpatients were reviewed prospectively for prescribed patterns of inhalers and anti- asthmatic and COPD drugs. The prescription guidelines, therapeutic guidelines, Micromedex, Medscape and references books will be used as tools to review the prescription and case chart. The admission register will be reviewed for prescription of any inhalers and antiasthmatic and COPD dugs. The case sheet, treatment chart, physician notes will be subjected for capturing any information related to the study.

All medically relevant information was noted in a predefined data collection form. Alternatively, these case charts were reviewed for prescription of inhalers and antiasthmatic drugs. The demographic data and the detailed history of patient regarding past, present, family, personal and drug history was taken. The other details like the present diagnosis, reason for the present admission, any investigations done to confirm the diagnosis were also noted.

Also found drug interactions of inhalers and anti-asthmatic drugs and drug selection, dosage forms, route, frequency, indication were also studied. The proper inhalation technique was assed using the questionnaires there were 11 steps for MDI and 12 steps for MDI + spacer each correct technique carried a score of 1 and wrong technic carried 0 .

The adherence to the inhaler technique was assed using the formula correct dose/incorrect dose $* 100$ and the reasons for no adherence were also noted. The therapeutic inappropriateness of prescribed inhalers and anti-asthmatic drugs is determined with standard guidelines. The changes and the daily notes in the case sheets were followed until the patient is discharged. The cost involved in use of inhalers in therapeutic inappropriateness also considered. All data was timely updated and analysed by using suitable software. 


\section{RESULTS AND DISCUSSION}

In our study out of 180 patients $55.4 \%$ were diagnosed with COPD and $45.6 \%$ were asthmatic, out of which $31.6 \%$ were men $15 \%$ females were asthmatics and $48.3 \%$ males and $5 \%$ female were of COPD. $14.1 \%$ males and $7.5 \%$ female asthmatics were of the age group 46-64 years. $19.1 \%$ males and $0.8 \%$ females of COPD were of the age group 46-64 years. Highest number of patient's i.e. $18.3 \%$ males, $9.1 \%$ female asthmatics, $23.3 \%$ males and $3.3 \%$ female asthmatics had the disease ranging from 1-10 years. Among asthmatic patients $7.5 \%$ male were smokers and $3.3 \%$ men were alcoholic. Among COPD patients $26.6 \%$ men were smokers and $5.8 \%$ men were alcoholics. In our study population about $10.8 \%$ asthmatics and $20 \%$ COPD patients were prescribed with budesonide MDI. About 10\% asthmatics and 9.1 COPD patients were prescribed with budesonide MDI+spacer. About $4.1 \%$ asthmatics and $2.5 \%$ COPD patients were prescribed with salbutamol MDI. About $17 \%$ asthmatics and 10\% COPD patients were prescribed with mdi ipratropium and $8 \%$ asthmatics and $12.5 \%$ COPD patients were prescribed with ipratropium MDI+spacer. Table 1

Table 1: Usage pattern of inhalers in study population

\begin{tabular}{|c|c|c|c|c|c|c|c|c|c|c|c|c|c|c|}
\hline \multirow{2}{*}{$\begin{array}{l}\text { Class of } \\
\text { drug } \\
\text { I }\end{array}$} & \multirow{2}{*}{$\begin{array}{l}\text { Name } \\
\text { of the } \\
\text { drug } \\
\Pi\end{array}$} & \multirow{2}{*}{$\begin{array}{l}\text { Dosage } \\
\text { form } \\
\amalg\end{array}$} & \multicolumn{6}{|c|}{$\begin{array}{c}\text { Asthma } \\
(n=97)\end{array}$} & \multicolumn{6}{|c|}{$\begin{array}{l}\text { COPD } \\
(\mathrm{n}=83)\end{array}$} \\
\hline & & & $\mathbf{M}$ & $(\%)$ & $\mathbf{F}$ & $(\%)$ & $\begin{array}{l}\text { Tota } \\
1\end{array}$ & $(\%)$ & $\mathbf{M}$ & $(\%)$ & $\mathbf{F}$ & $(\%)$ & $\begin{array}{l}\text { Tota } \\
1\end{array}$ & $(\%)$ \\
\hline $\begin{array}{l}\text { corticosteroi } \\
\text { ds }\end{array}$ & $\begin{array}{l}\text { budeson } \\
\text { ide }\end{array}$ & $\begin{array}{l}\text { MDI } \\
\text { NEBULIZE } \\
\text { R } \\
\text { MDI+SPAC } \\
\text { ER }\end{array}$ & $\begin{array}{l}12 \\
4 \\
9\end{array}$ & $\begin{array}{l}(10) \\
(3.3) \\
(7.5)\end{array}$ & $\begin{array}{l}1 \\
0 \\
3\end{array}$ & $\begin{array}{c}(0.8) \\
(0) \\
(2.5)\end{array}$ & $\begin{array}{c}13 \\
4 \\
12\end{array}$ & $\begin{array}{l}(10.8) \\
(3.3) \\
(10)\end{array}$ & $\begin{array}{l}23 \\
2 \\
7\end{array}$ & $\begin{array}{l}(19.1) \\
(1.6) \\
(5.8)\end{array}$ & $\begin{array}{l}1 \\
0 \\
4\end{array}$ & $\begin{array}{c}(0.8) \\
(0) \\
(3.3)\end{array}$ & $\begin{array}{c}24 \\
2 \\
11\end{array}$ & $\begin{array}{l}(20) \\
(1.6) \\
(9.1)\end{array}$ \\
\hline $\begin{array}{l}\text { Beta } 2 \\
\text { agonists }\end{array}$ & $\begin{array}{l}\text { salbuta } \\
\text { mol }\end{array}$ & MDI & 4 & (3.3) & 1 & $(0.8)$ & 5 & $(4.1)$ & 3 & $(2.5)$ & 0 & & 3 & $(2.5)$ \\
\hline $\begin{array}{l}\text { Leukotrien } \\
\text { e modifiers }\end{array}$ & $\begin{array}{l}\text { Montelu } \\
\text { kast }\end{array}$ & Tablet & 36 & (30) & 9 & $(7.5)$ & 45 & $(37.5)$ & 7 & $(5.8)$ & 2 & $(1.6)$ & 9 & $(7.5)$ \\
\hline $\begin{array}{l}\text { Methyl } \\
\text { xanthanes }\end{array}$ & $\begin{array}{l}\text { Theoph } \\
\text { ylline }\end{array}$ & Tablet & 86 & (7.16) & 5 & (4.1) & 91 & $(0.7)$ & 30 & (25) & 4 & $(3.3)$ & 34 & $(28.3)$ \\
\hline Mucolytics & $\begin{array}{l}\text { Guaifen } \\
\text { esin }\end{array}$ & Syrup & 2 & $(1.6)$ & 4 & $(3.3)$ & 6 & (5) & 5 & $(4.1)$ & 2 & (1.6) & 7 & $(5.8)$ \\
\hline $\begin{array}{l}\text { Antihistam } \\
\text { ine }\end{array}$ & $\begin{array}{l}\text { Cetirizi } \\
\text { ne }\end{array}$ & Tablet & 12 & (10) & 1 & $(0.8)$ & 13 & $(10.8)$ & 2 & $(1.6)$ & 1 & $(0.8)$ & 3 & $(2.51)$ \\
\hline $\begin{array}{l}\text { Anticholine } \\
\text { rgics }\end{array}$ & $\begin{array}{l}\text { Ipratrop } \\
\text { ium } \\
\text { bromide }\end{array}$ & $\begin{array}{l}\text { MDI } \\
\text { MDI+SPAC } \\
\text { ER }\end{array}$ & $\begin{array}{l}17 \\
5\end{array}$ & $\begin{array}{c}(14.1) \\
(4.1)\end{array}$ & $\begin{array}{l}0 \\
3\end{array}$ & $(2.5)$ & $\begin{array}{l}17 \\
8\end{array}$ & $\begin{array}{l}(14.1) \\
(6.6)\end{array}$ & $\begin{array}{l}10 \\
14\end{array}$ & $\begin{array}{l}(8.3) \\
(11.6)\end{array}$ & $\begin{array}{l}2 \\
1\end{array}$ & $\begin{array}{l}(1.6) \\
(0.8)\end{array}$ & $\begin{array}{l}12 \\
15\end{array}$ & $\begin{array}{c}(10) \\
(12.5)\end{array}$ \\
\hline
\end{tabular}

There were 77 drug interactions which were come across in our study population out of $8.3 \%$ males and $2.5 \%$ females are found to have interaction with theophylline+azithromycin which leads to QT prolongation which was highest. In our study adherence to inhaler therapy was assessed by using the formula correct dose/incorrect dose*100 and the following were the adherence $\%$ for the inhaler drugs budesonide mdi80\% among both male and female asthmatics $86 \%$ males and $55 \%$ females were prescribed with budesonide mdi among COPD. $76.7 \%$ males and $83.4 \%$ female's asthmatics are prescribed with budesonide MDI+spacer $86 \%$ males and $84.9 \%$ females COPD patients are prescribed with MDI+spacer.

Table 2: Inhaler usage in study asthma and COPD patients before pharmacist intervention

\begin{tabular}{|c|c|c|c|c|c|c|}
\hline & \multicolumn{6}{|c|}{ No. of patients preferred correctly } \\
\hline Questionnaire & $\begin{array}{c}\text { Male } \\
(\mathrm{n}=96)\end{array}$ & $(\%)$ & $\begin{array}{l}\text { Female } \\
(n=24)\end{array}$ & $(\%)$ & Total & $(\%)$ \\
\hline Shake vigorously & 88 & $(73.3)$ & 17 & $(14.1)$ & 105 & $(90.8)$ \\
\hline Remove cap & 92 & $(76.6)$ & 19 & $(15.8)$ & 111 & $(92.5)$ \\
\hline Hold upright & 95 & $(79.1)$ & 17 & $(14.1)$ & 112 & $(93.3)$ \\
\hline $\begin{array}{c}\text { Breathe out gently } \\
\end{array}$ & 86 & $(71.6)$ & 16 & $(13.3)$ & 102 & $(85)$ \\
\hline Start breathing in slowly and deeply & 77 & $(64.1)$ & 16 & $(13.3)$ & 93 & $(77.5)$ \\
\hline Actuate during inspiration & 89 & $(74.1)$ & 20 & $(16.6)$ & 109 & $(90.8)$ \\
\hline Continue slow inhalation & 89 & $(74.1)$ & 19 & $(15.8)$ & 108 & $(90)$ \\
\hline Release in spacer and inhale & 85 & $(70.8)$ & 19 & 15.8) & 104 & $(86.6)$ \\
\hline No aerosol loss is visible & 82 & $(68.3)$ & 19 & $(15.8)$ & 101 & $(84.1)$ \\
\hline Hold breath for 10 seconds & 78 & $(65)$ & 15 & $(12.5)$ & 93 & $(77.5)$ \\
\hline Next dose after 1 minute & 89 & $(74.1)$ & 17 & $(14.1)$ & 106 & $(88.3)$ \\
\hline Rinse out mouth after using & 22 & $(18.3)$ & 7 & $(5.8)$ & 29 & $(24.1)$ \\
\hline
\end{tabular}


Table 3: Inhaler usage in asthma and COPD patients after pharmacist intervention

\begin{tabular}{|c|c|c|c|c|c|c|}
\hline & \multicolumn{6}{|c|}{ No. of patients preferred correctly } \\
\hline Questionnaire & $\begin{array}{l}\text { Male } \\
\left(\mathbf{n}_{=96)}\right.\end{array}$ & $(\%)$ & $\begin{array}{c}\text { Female } \\
(n=24)\end{array}$ & $(\%)$ & Total & $(\%)$ \\
\hline Shake vigorously & 97 & $(80.8)$ & 22 & $(18.3)$ & 119 & $(99.1)$ \\
\hline Remove cap & 97 & $(80.8)$ & 23 & $(19.1)$ & 120 & $(100)$ \\
\hline Hold upright & 94 & $(78.3)$ & 23 & (19.1) & 117 & $(97.5)$ \\
\hline Breathe out gently & 95 & $(79.1)$ & 23 & $(19.1)$ & 118 & $(98.3)$ \\
\hline $\begin{array}{l}\text { Start breathing in slowly and } \\
\text { deeply }\end{array}$ & 91 & (75.8) & 21 & $(17.5)$ & 112 & $(93.3)$ \\
\hline Actuate during inspiration & 95 & $(79.1)$ & 19 & $(15.8)$ & 114 & $(95)$ \\
\hline Continue slow inhalation & 94 & $(78.3)$ & 23 & $(19.1)$ & 117 & $(97.5)$ \\
\hline Release in spacer and inhale & 92 & $(76.6)$ & 22 & $(18.3)$ & 114 & $(95)$ \\
\hline No aerosol loss is visible & 88 & $(73.3)$ & 20 & $(16.6)$ & 108 & $(90)$ \\
\hline Hold breath for 10 seconds & 90 & $(75)$ & 21 & $(17.5)$ & 111 & $(92.5)$ \\
\hline Next dose after 1 minute & 95 & $(79.1)$ & 22 & $(18.3)$ & 117 & $(97.5)$ \\
\hline Rinse out mouth after using & 39 & $(32.5)$ & 11 & $(9.1)$ & 50 & $(41.6)$ \\
\hline
\end{tabular}

In our study adherence to inhaler therapy was assessed by using the formula correct dose/incorrect dose*100 and the following were the adherence $\%$ for the inhaler drugs budesonide mdi80\% among both male and female asthmatics $86 \%$ males and $55 \%$ females were prescribed with budesonide mdi among copd. $76.7 \%$ males and $83.4 \%$ female's asthmatics are prescribed with budesonide mdi+spacer $86 \%$ males and $84.9 \%$ females COPD patients are prescribed with mdi+spacer(Table 2). In a retrospective study by thamby SA et al. on drug utilization pattern in asthmatics it is seen that the study focused on both smoker and non smoker asthmatics. It was observed that salbutamol was most commonly prescribed, followed by montelukast and prednisolone. In the combination therapy, the most commonly prescribed was Symbicort, followed by seretide and combivent. Corticosteroids constituted the most prevalent class, followed by beta-2 agonists, leukotriene modifiers and methylxanthines. The study presented the most recent scenario on drug utilization pattern of asthmatics in Kedah state ${ }^{10}$.

The reasons for non-adherence were noted where $6.6 \%$ were not adherent due to high cost of medicine $0.8 \%$ due to lack of access to hospital drug store, $4.1 \%$ due to fear of side effects, $10 \%$ felt better and stopped, $1.6 \%$ forgotten / occupational problems, $3.3 \%$ lack of family support, $5 \%$ didn't adhere due to fear of becoming dependent on treatment (Table 3). In a similar study by Fugate AR on medication adherence in COPD and asthma patients it was found that The major reported reasons to stop/miss medication were felt better and stopped $(64.81 \%)$ because asthma and COPD has symptomatic treatment, so whenever feel better they stop the medicine, forgetfulness (55.55\%), expensive (42.59\%) and lack of access to drug store/hospital (31.48\%). Other minor reasons were lack of family support/Motivation, fear of side effects, feel non beneficial. The same reasons were reported in previous studies

\section{CONCLUSION}

The present results highlight the need for pharmacist interventions aimed at improving adherence to inhalers in COPD and asthmatic patients.

Overall medication adherence and inhaler technique improvement was found to be statistically significant in asthma and COPD patients after counseling by pharmacist.

The major reasons for medication non-compliance were felt better and stopped, high cost of medication, forgetfulness and lack of access to drug store/hospital.

\section{REFRENCES}

[1]. Ali Arab , Shibi Mary Thomas, Dr. Raju Koneri, Nastaran Talank. A prospective study on prescribing pattern of pulmonary inhalers in inpatient at a tertiary care hospital, case study Baptist hospital, Bangalore, Karnataka. Int. J. Adv. Multidiscip. Res. (2016). 3(6): 117-121

[2]. Al-Showair RA, Tarsin WY, Assi KH, Pearson SB, Chrystyn H. Can all patients with COPD use the correct inhalation flow with all inhalers and does training help? Respir Med. 2007;101:2395-401.

[3]. Burney J, Luczynska C, Chinn S, Jarvis D. The European Community Respiratory Health Survey II. Eur Respir J. 2002;20:1071-79

[4]. Global Strategy for Asthma Management and Prevention. Global initiative for asthma (gina). 2012; Available at http://www.ginasthma.org/. Accessed October 2013. 
[5]. Global Strategy for the Diagnosis Management and Prevention of COPD. Global initiative for chronic obstructive lung disease (gold). 2014; Available at http://www.goldcopd.org/. Accessed February 2014.

[6]. Hardwell A, Barber V, Hargadon T, McKnight E, Holmes J, Levy ML. Technique training does not improve the ability of most patients to use pressurised metered-dose inhalers (pMDIs). Prim Care Respir J. 2011;20:92-6.

[7]. Melani AS, Bonavia M, Cilenti V, Cinti C, Lodi M, Martucci P, et al. Inhaler mishandling remains common in real life and is associated with reduced disease control. Respir Med 2011;105:930-8.

[8]. Sanchis J, Corrigan C, Levy ML, Viejo JL. Inhaler devices - from theory to practice. Respir Med 2013;107:495-502.

[9]. Vitull K. Gupta, JaGJeet SinGh Bahia, aShwani MaheShwari, Sonia arora, Varun Gupta, Sahil nohria. To Study the Attitudes, Beliefs and Perceptions Regarding the Use of Inhalers among Patients of Obstructive Pulmonary Diseases and in the General Population in Punjab. Journal of Clinical and Diagnostic Research. 2011 June, Vol-5(3): 434-439 